\title{
A Case Study of Elementary Teachers' Use of Instruction Time in Mathematics
}

\author{
Wei-Min Hsu' ${ }^{1}$, Huan-Hsieh Kuo ${ }^{2}$ \\ ${ }^{1}$ Department of Science Communication, National Pingtung University, Taiwan \\ ${ }^{2}$ Hsien-Chi Elementary School, Taiwan \\ Email: ben8535@mail.nptu.edu.tw
}

How to cite this paper: Hsu, W.-M., \& Kuo, H.-H. (2016). A Case Study of Elementary Teachers' Use of Instruction Time in Mathematics. Creative Education, 7, 25592575.

http://dx.doi.org/10.4236/ce.2016.717242

Received: August 9, 2016

Accepted: October 31, 2016

Published: November 3, 2016

Copyright $\odot 2016$ by authors and Scientific Research Publishing Inc. This work is licensed under the Creative Commons Attribution International License (CC BY 4.0)

http://creativecommons.org/licenses/by/4.0/

\begin{abstract}
This study probed into elementary school teachers' use of instruction time in mathematics on the basis of a case study. Recording a teacher with 20 years' teaching experience in his classroom and having interviews with him for six months, this study aims to understand the teacher's use of mathematics instruction time and the influencing factors on this case. According to the results, the teacher in this case tends to divide his teaching activities into review and preview, new content development, interactions and discussions, and exercises and applications. In each class, he would carry out these activities. As the teaching of a module advanced, less instruction time is spent on new content development and more on interactions, discussions, exercises and applications. In terms of the factors influential on the instruction time use, the teacher in this case takes into account mainly the students' learning initiatives in mathematics and their learning motives, and rarely considers other factors.
\end{abstract}

\section{Keywords}

Elementary Teachers, Use of Instruction Time, Mathematics Teaching

\section{Introduction}

Teaching in the classroom is the most important factor for students' mathematics learning (Boaler \& Staples, 2008; Gutstein, 2003; Hiebert \& Grouws, 2007). Mathematics teaching, however, is a complicated phenomenon, which makes the analysis of it a difficult task. Hiebert and Grouws (2007) suggested that teaching should be comprised of the interactions between students and teachers on the learning content, and aimed to help students achieve the learning goals. Inspired by this definition, many studies have been conducted in the past from various perspectives to probe into and analyze ma- 
thematics teaching. Artzt and Armour-Thomas (2002) analyzed from the three dimensions of the mathematics problems used by the teachers, the learning environment created by the teachers and the interactions between teachers and students. Henningsen and Stein (1997), Hsu (2013a) focused on mathematics teaching, and analyzed mathematics problems as the unit, the type of mathematics problems, how they were proposed and solved as the subjects of analysis. Hiebert et al. (2003) analyzed the mathematics teaching in a variety of countries from aspects such as the presentation and functioning of mathematics problems, types of the problems, homework assignments, and resources available. Stein, Remillard and Smith (2007) suggested that researchers should try to understand the influence of teaching on students' mathematics learning through the analysis of the sources, types and implementation of mathematics problems.

These studies all conducted with mathematics problems as the focus, and set to analyze the performance of mathematics teachers from such aspects as the presentation of the problems, interactions between students and teachers, and learning environment. The reason for this was that the mathematics curriculum was comprised of mathematics problems (Hsu, 2013b; Stein, Remillard, \& Smith, 2007) and most teachers tended to conduct teaching on the basis of the mathematics problems in the textbooks (Grouws, Smith, \& Sztajn, 2004; Hsu, 2013c). However, apart from starting the analysis from the mathematics problems, could mathematics teaching be analyzed from other perspectives? After reviewing the literature on mathematics teaching and learning in the past several decades, Hiebert and Grouws (2007) put forward a key influence factor on students' mathematics learning, namely the Opportunity To Learn (OTL). OTL, on the other hand, covered a range of issues including the scope set by the teacher for the teaching content, teachers' expectations on the students, types of problems used in teaching, the allocation and use of instruction time, etc. Later, Grouws et al. (2013) examined the OTL provided by the teachers with the scope they set for the teaching content. This definition, however, is not applicable to Taiwan with its national curriculum, according to which all the content in the curriculum needs to be covered in the teaching. Given moreover that teachers' expectations are difficult to be observed and measured and that many studies at home and abroad have already touched upon the types of mathematics problems and interactions between students and teachers during their execution, only the use and allocation of mathematics instruction time is an area rarely delved into by the scholars. Since it is a key factor in OTL and influential on students' mathematics learning (Grouws et al., 2010), investigations on the use of instruction time in mathematics are therefore worthy to be conducted.

Today, after over 20 years of mathematics education reform in Taiwan, it is time to conduct studies on teachers' use and allocation of mathematics instruction time to understand the outcomes of this reform from at least this aspect. However, as these studies are still in the exploratory stage, case studies are favored given also the complex range of factors. A senior teacher with over twenty years of working experience is therefore invited to participate in this study. Focusing on instruction time, it is hoped 
that this study could achieve the following two goals:

1) To understand the teacher's use and allocation of mathematics instruction time;

2) To probe into the factors influential on the teacher's use of instruction time in this case.

\section{Literature Review}

Mathematics teaching consists of all the activities involving both the teacher and students (Cuban, 1992; Remillard, 2005). In order to understand teachers' use of instruction time in mathematics, it is therefore necessary to firstly probe into the teaching activities implemented by the mathematics teacher. And only in this way will it be possible to investigate the teacher's use and allocation of time to different activities. In this chapter, attempts will be firstly made to understand the activities taking place in a mathematics classroom and then the factors influential on mathematics teaching on the basis of relevant literature, the aim of which is to establish the framework and theoretical basis for the analyses in this study.

\subsection{Teaching Activities Taking Place in the Mathematics Classroom}

Good and Grouws (1979) was one of the earliest studies on the effective mathematics instructional behaviors. They suggested that these behaviors should include review, development, seatwork, homework assignment, and special review. Among them, the review took usually about eight minutes and meant reviewing the concepts and skills associated with the homework, namely the content taught in the previous class. The next approximately twenty minutes would be focused on the study of new skills and concepts. Explanations and demonstrations would be used to promote the students' understanding and student comprehension would be assessed. In the next 15 minutes, the students would be provided uninterrupted successful practice so that the students could use the skills and concepts they had just learned to solve problems. It was also necessary to check the students' work at the end of this period. The last activity was homework assignment so that students would be made to review or practice at home. Special review, on the other hand, referred to the overall review conducted on a weekly or monthly basis to review the skills and concepts covered during the previous week or month. According to Good and Grouws (1979), mathematics teaching includes at least the following three main activities: review of related concepts, development of new concepts and practices and applications concerning the new concepts, as homework assignment takes usually a short time and special review is not conducted on each class.

According to a recent study, the most frequently seen mathematics teaching activities included the students answering questions from the textbooks or learning worksheet, calculation, review via homework assignment, and the use of mathematics concepts to explain and solve problems (Weiss, Banilower, McMahon, \& Smith, 2001; Weiss, Pasley, Smith, Banilower, \& Heck, 2003). The Trend in International Mathematics and Science Survey (TIMSS) also found that most of mathematics instruction time was spent on the review of homework, teachers' explanations of new concepts, teachers' 
guiding the students in practices and the students' independent practices (Mullis et al., 2000). In its analysis of the videos on the mathematics teaching in seven different countries, TIMSS 1999 also focused on the three activities of review, introduction of new content and practices concerning the new content (Hiebert et al., 2003). It was found that the mathematics teaching in Asian (Hong Kong and Japan) were dominated by teachers' lectures, including in the process of reviewing, introducing new content and practices. Among them, the explanation and presentation of new content was most time-consuming (Leung, 2005). From the above studies, it could be seen that all mathematics teaching in the classroom is comprised of the review of related concepts, explanation and development of new concepts and the practices concerning the new content.

During the mathematics curriculum reform in recent years, different claims have been made in terms of the implementation of teaching activities in the classroom. The Grade 1 - 9 Mathematics Curriculum in Taiwan, for example, given its emphasis on the connections with real life and the development of communication skills, results in the design of the situational page in the textbooks and presentation of different lines of thought for the solution of one problem. In this way, students could learn mathematics from real life experiences and develop their capacities for diversified thinking and communication (Hsu, 2013b). In his study on the differences between the reformoriented and tradition-oriented curriculum in terms of the use of instruction, Grouws et al. (2010) suggested that the reformed curriculum placed more emphasis on the preview of learning content, the exploration of concepts, sharing and discussion. Artzt and Armour-Thomas (2002) also argued that whether a teacher's mathematics teaching was in line with the claims in the reform should be analyzed from the three aspects of the presentation of mathematics problems, creation of learning environment and interactions between teachers and students. Combining the findings of past studies and substance of the curriculum reform, this study probed into teachers' use and allocation of instruction time on four teaching activities, namely review of previous materials and preview of new materials, development of new content, interactions and discussions, practices and applications.

\subsection{Factors Influential on the Teacher's Mathematics Teaching}

Mathematics instruction is the instructional performance converted from a teacher's knowledge and beliefs under a particular environmental context (Fennema \& Franke, 1992). In other words, teacher's knowledge and beliefs are key influence factors on his or her instructional performance (Grouws et al., 2013; Sandt, 2007; Tarr, Reys, Reys, Chávez, Shih, \& Osterlind, 2008). Viewed from the implementation or use of the curriculum, teachers are using the mathematics problems from the textbooks most of the time (Grouws et al., 2004; Stein, Remillard, \& Smith, 2007). During the course of implementing instruction, therefore, the personal knowledge and beliefs of a teacher will interact with the content of the textbooks, namely the subjective characteristics will interact with the objective characteristics. Teachers will moreover take the personalities 
and performances of the students, and the current environmental context into consideration (Remillard, 2005). In the study on the use of textbooks, Hsu (2013c) found that teachers tend to consider more the factors relating to themselves and the students, and less on the influences of textbooks and the context. Henningsen and Stein (1997) suggested that under the influence of students and the context, teachers will present the cognitively demanding mathematics problems in a closed dialog and in a way that emphasizes memorization. In the study on pre-service teachers, Lloyd (2008) found that teachers' instructional performance are influenced by the context of the teaching field, his or her mathematics knowledge and attitude, and the characteristics of textbooks. Boaler and Staples (2008) also suggested that teachers' personal mathematics instruction beliefs and positioning will affect their choice and implementation of mathematics problems, thus influencing their instructional performance.

Although conducted with different methods, on different subjects and from different perspectives, the studies reviewed above have all come to similar conclusions. Namely, teachers' instruction implementation will be affected by such factors as the teacher's intrinsic properties, the students $s /$ he is faced with, the context $s /$ he is in and textbooks used for the instruction. This could be used as a reference for this study in the investigation of the factors influential on the teacher's use of instruction time.

\section{Research Method and Implementation}

\subsection{Research Method}

Teacher's use of mathematics instruction time has so far been a topic getting little attention from the mathematics education community. As the use of instruction time is often highly personalized in terms of the process and its results, cases studies are favored for exploratory studies on such topics. Only in this way could its implementation and relevant influence factors be investigated in an in-depth manner later (Hsu, 2013c). This method is used also because most previous studies on instruction implementation (Hsu, 2013a; Lloyd, 2008), and teacher performance (Borko \& Livingston, 1989; Even, Tirosh, \& Robinson, 1993) are also conducted through case studies. Given the exploratory and complicated nature of instruction time as a research topic and by referring to the methods adopted in relevant studies in the past, this study used case study as the research method. A teacher with over twenty years' teaching experience was chosen as the subject of study, the aim of which was to probe into his use of instruction time on such four teaching activities as review and preview, development of new content, interactions and discussions, and practices and applications on a mathematics class. The factors influential on his use of instruction time were also part of the study.

\subsection{Research Subjects}

The teacher in this case study is currently working in an elementary school in South Taiwan. The teacher in this case (hereafter referred to as James) holds a master's degree in Science and Mathematics Education and has worked for 23 years as a teacher. Currently, he is the homeroom teacher for six-graders in his school. Located in the envi- 
rons of a city, the school James is working for has 18 classes. As the student parents are very concerned about how the students are doing in school, most of them are in close contact with him. Academically, the students are very used to his teaching style and able to keep up with the course progress. In his mathematics instruction, James attaches the greatest importance to the comprehension and application of concepts, rather than memorization and good calculation skills. His hope, therefore, is that every student could have the basic capacities for problem solving. Instead of following the content in the textbook closely, he would often stimulate the students' interest with real life experiences and sometimes guide the students to have discussions and summaries by designing the right questions at the right time. In order to train the students' capacities for practices and application, James often assigns some homework for the students to be completed at school or back at home. He would also ask the students with better performance to help those lagging behind.

\subsection{Data Collection}

\section{1) Teaching observation and recording}

In order to have a full understanding of James's use of mathematics instruction time, observations and recordings were conducted on his instruction of different mathematics topics, namely the three learning topics of numbers and quantity, geometry, and statistics and probability, that is "decimal division" (6 lessons), "cylinder and cone" (7 lessons) and "pie chart" (7 lessons), to be specific. Among them, the focus was given to decimal calculation on the curriculum materials concerning numbers and quantity, to the components of solid figures on the curriculum materials concerning geometry and to plotting and application of charts on the curriculum materials concerning statistics. That is to say, this study observed and recorded James having 20 lessons from October 2010 to March 2013. Observing and recording the teacher elaborating on each unit in a full manner, the aim was to understand the teacher's overall use and allocation of the instruction time, thus avoiding the errors possible in observations conducted at fixed time or on certain classes in a random manner (e.g.: observing only the first or last lesson of every unit). The focus of the observations, of course, was put on the teacher's use of time on the four major mathematics teaching activities, including review and preview, development of new content, interactions and discussions, and practices and applications.

\section{2) Interviews}

The interviews were conducted in order to know the factors influential on James's use and allocation of instruction time. Six interviews were conducted at three stages. Firstly, it was the stage prior to the research. The interview (once) was conducted to understand James's educational beliefs, teaching methods, how his students were doing academically, degree of support from the parents, his educational expectations and so on, thus approaching the orientations and state of his teaching from an overall perspective and providing the basis for the interviews at the next stage. On the second stage, interviews (three times, same with the number of units) were conducted at the end of 
each unit. After analyzing James's use of instruction time on the four teaching activities in a preliminary manner, the interviews were conducted to understand the use of instruction time on the different sessions in a unit or on different teaching activities. The third-stage interview was conducted after the study was over. Based on the overall allocation of instruction time, the aim was to confirm the factors influential on James's use of instruction time when it came to different modules (once). In addition, since James integrated information technologies into his teaching of the module Cylinder and Cone, an extra interview was conducted to understand the influential factors in this case.

\subsection{Data Processing and Analysis}

\section{1) Calculation of the time for each teaching activity}

As this study was firstly aimed to understand James's use of instruction time on the four teaching activities of review and preview, development of new content, interactions and discussions, and practices and applications, the data collected in the observation will be categorized and analyzed according to these teaching activities. Among them, "review and preview" refers to James's review of related concepts or skills, preview of the content to be covered, establishment of connections between the old and new concepts, or between the new learning content and students' existing experience at the beginning of a lesson, all conducted with the aim to link the new concepts with the previous ones and prepare the students for the new learning content. "Development of new content" refers to the activities implemented to officially teach the new content, including the presentation of mathematics concepts with different representations, the explanation of the methods to solve a problem or methods of calculation, the elaboration on the possible misconceptions, the demonstration and illustration of the nature or definition of a concept, all conducted with the aim to help the students comprehend the new mathematics concepts or skills. "Interactions and discussions" refer to James's asking the students to have interactions and discussions on particular problems during the course of his instruction, and his inviting the students to make presentations on or share with other students the results of their discussions. These activities were conducted to check students' comprehension and thinking, besides giving James the opportunity to further clarify on the points the students thought much about or were puzzled about. "Practices and applications" refer to the problems or homework teachers assigned to the students during the course of his instruction, so that students could use the skills or concepts they have just learned to solve problems, thus consolidating their learning of new concepts and skills. The time devoted to each teaching activity was calculated and recorded as "mm'ss". Four minutes and 20 seconds, for example, was recorded as “4' 20 ”.

In order to ensure the reliability of the data and prevent the researcher's subjective ideas from influencing the presentation of the data, two analysts were relied on in this study for the triangulation. The second author and another graduate student majoring in Mathematics Education were asked to categorize the teaching activities and calculate 
their time after watching the recording of one of James's lessons. As it turned out, the categorizations of teaching activities were basically the same while slight differences were seen in the calculation of the time for each teaching activity. The main reason for the differences came from the determination of the wait time between the different teaching activities. The calculation of the time for each teaching activity in the teaching videos did not begin therefore only after ideas were exchanged and it was decided that all the time before the next teaching activity began should belong to the previous activity.

\section{2) Analysis of the interview data}

As this study was aimed secondly to probe into the factors influential on teachers' use of instruction time, interviews were conducted and the data collected from these interviews were categorized. It was hoped that these factors could be understood from the proportion and content of each category. After the interviews were converted into transcripts, therefore, they were numbered in the form of "interviewee-date". With the teacher in this case study represented with letter "J" and the date with " $\mathrm{mm} / \mathrm{dd}$ ", "J1012" meant therefore the interview with James conducted on October 12. After the transcription and numbering, in order to avoid the influence of subjective ideas, the analysis on the interview data was conducted in the same way as it was done in Hsu (2013c). Namely, with the interview conducted on a main topic as the unit, two analysts were asked to categorize the interview data drawn from the relevant video. The main topic here referred to the factors influential on James's teaching. Although it has been suggested in relevant past studies that the factors influential on a teacher's instructional performance include personal knowledge and beliefs, students, textbooks, context, etc., we kept an open mind throughout the analysis and conducted the categorization process according to the interview content. After the two analysts communicated and discussed with each other on the unit of analysis and definition of the categories, they conducted their respective analyses on James's interview content. The scorer reliability was represented as $(2 \mathrm{M} /(\mathrm{M} 1+\mathrm{M} 2)$, among which $\mathrm{M}$ referred to the number of items that were classified into the same category by the two scorers and M1 \& M2 referred to number of items that were categorized differently by the two scorers. The aim was to establish the consistency of the data analysis. The scorer reliability was 0.91 . After that, the two analysts had discussions on the inconsistencies between the two analysts and did not continue with the categorization of the interview data before they agreed with each other.

\section{3) Reliability and validity of the data}

The reliability of data in this study was established through scorer reliability. Both majoring in Mathematics Education and having over nine years of experience working as a mathematics teacher, the two analysts have moreover come to the same results as to the categorization of the teaching activities. In terms of the slight differences they had in the calculation of the wait time between different teaching activities, they were also resolved after some discussions. As for the analysis of interview data, the scorer reliability was 0.91 , with the inconsistencies also turned into consensus after some discussions. The 
results of the data analysis conducted in this study were therefore quite reliable.

In terms of validity, both the categories of teaching activities, and the factors influential on a teacher's mathematics instruction were the results of integrating relevant studies at home and abroad. In terms of mathematics instructional activities or behaviors, such studies as Good and Grouws (1979), Weiss Banilower, McMahon, \& Smith, (2001), the analysis of mathematics teaching videos by TIMSS 1999 (Hiebert et al., 2003), and the study on the use of instruction time in mathematics from two different perspectives by Grouws et al. (2010), have all come to the conclusion that review and preview, development of new content, interactions and discussions, and practices and applications were the four types of activities taking place in a mathematics classroom. In terms of the factors influential on a teacher's use of instruction time, this study referred to the study on the use of textbooks by Hsu (2013c), the suggestions made in Remillard (2005) on using curriculum, the study on pre-service teachers' use of curriculum in Lloyd (2008) and the research findings of Stein, Remillard and Smith (2007), all of which pointed out that teachers themselves, students, textbooks and context constituted the main factors influential on a mathematics teacher in his or her class. In other words, the categorization of data in this study was both theoretically and practically based. The results generated from the analysis, therefore, should be able to reflect teachers' use of mathematics instruction time and the influence factors in an effective manner. In addition, the observation data and interview data was compared to confirm the factors influential for James.

\section{Research Results and Discussion}

\subsection{James's Allocation of Mathematics Instruction Time Constitutes a Stable Pattern}

Table 1 lists the use and allocation of instruction time on 20 lessons featuring different topics. From Table 1, it could be seen that James has conducted the four types of teaching activities in the teaching of each topic and in every lesson. It is also found that the amount of time allocated to each teaching activity is quite stable in every lesson. Generally speaking, he spends the most time on the development of new content, devoting about 17.0 minutes of each lesson on the explanation or demonstration of new concepts or skills. He allocates a slightly greater amount of time on practices and applications than on the interactions and discussions between students and the teacher, spending about 8.2 minutes and 7.3 minutes on each activity in every lesson. Although he might seem to have spent the least time on review and preview, James tends to spend an average of 4.5 minutes on this activity in every lesson in order to establish for the students the connections between old and new concepts or skills. If taken the unit as the basic unit, the changes in the use of instruction time on each teaching activity in different lessons of the same unit could be represented as Figure 1, from which it could be seen that the amount of time devoted to review and preview tends to decrease as the lessons advance. This is also true when it comes to the development of new content. In terms of the time spent on discussions and interactions and practices and applications, 
Table 1. Table of James's use of mathematics instruction time.

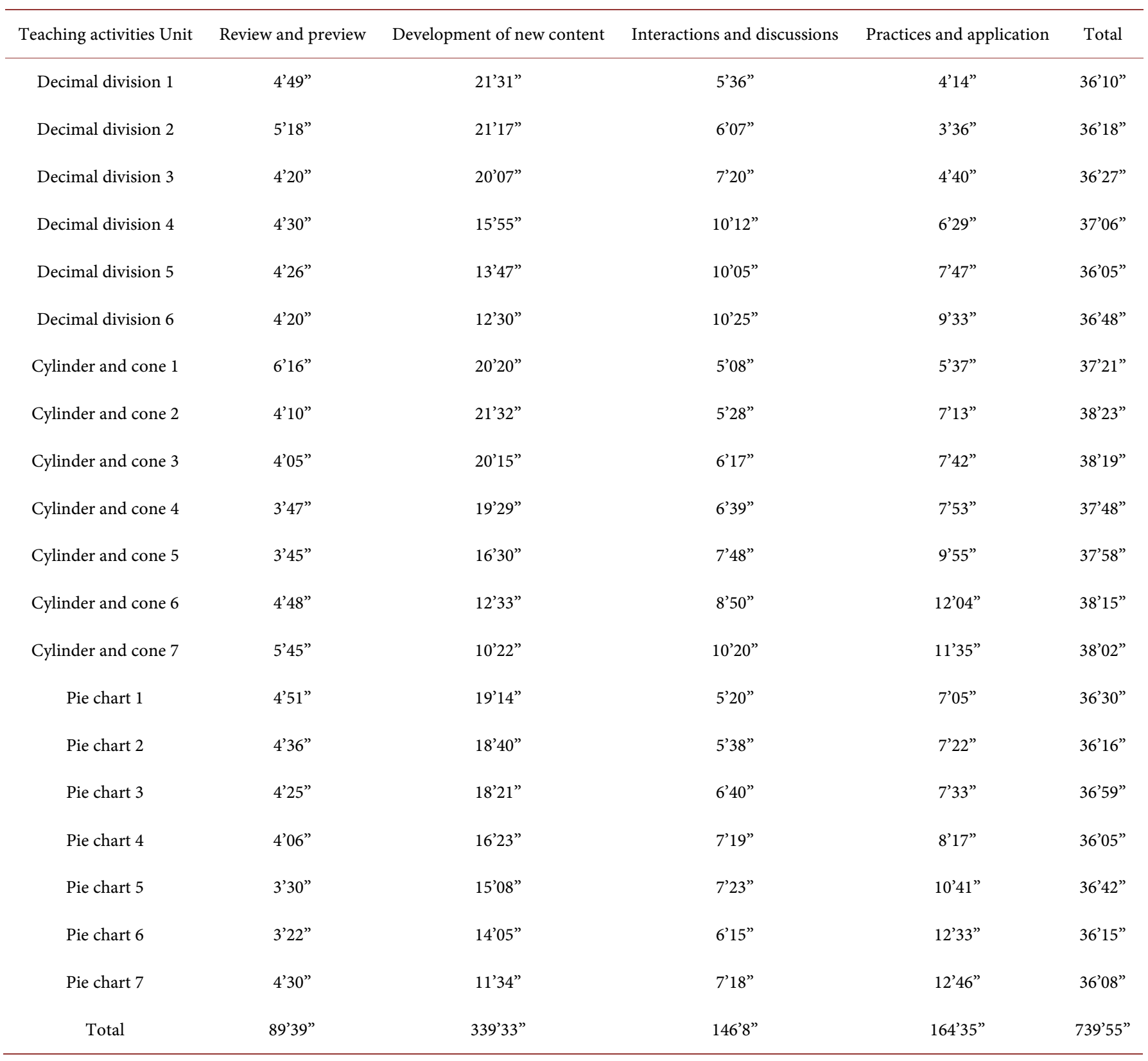

the amount of instruction time seems to increase as the lessons advance. This trend indicates that James would spend more time on the building the links between new and old knowledge and the explanation of concepts at the beginning of a unit. After that, he would gradually spend more time on interactions, discussions, practices and applications in order to understand and check the students' comprehension and application. A very stable pattern is found in James's use and allocation of mathematics instruction time, which does not change as the topic varies. Viewing from the total amount of instruction time, James has spent about 740 minutes on the instruction, an average of 37.0 minutes in each lesson, which takes up $93 \%$ of the total 40 minutes. 

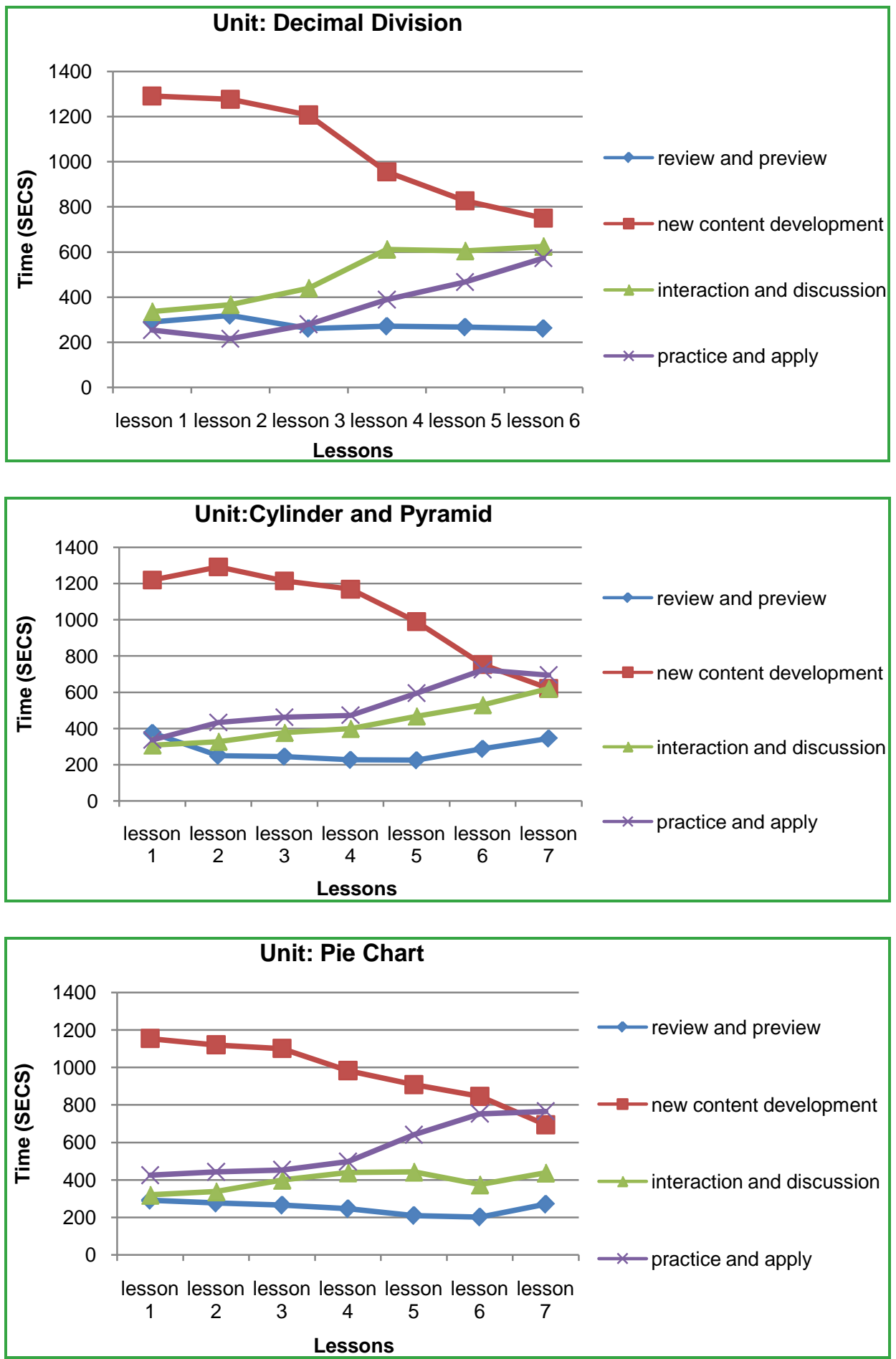

Figure 1. Trend of use of mathematics teaching time of James.

\subsection{Influential Factors on James's Use of Instruction Time}

The 27 analyzable units of interviews with the teacher in this case study could be categorized as relating to the "teacher", the "students", "textbook" and "context" in terms of content. Among them, the category in the interview data relating to the teacher himself 
covers the teacher's personal opinions on mathematics teaching and learning, including his opinions on the focuses, implementation and goals of mathematics teaching. The category relating to the students refers to the individual differences and interest of the students taken into account by the teacher during his instruction implementation, while the category relating to textbooks covers the factors concerning the content of the textbooks or teaching materials prepared by the teacher himself. Context refers on the other hand, to the pressure felt by the teacher because of the teaching schedule. Of these four categories, factors relating to the teacher himself have taken up most of James's attention during his teaching, which accounts for $40.8 \%$ of the total (11/27). Next are the student factors, which take up $33.3 \%$ of the total (9/27). Textbook factors account for $22.2 \%$ of the total $(6 / 27)$ while contextual factors are least important in this case, accounting only for the rest $3.7 \%(1 / 27)$. The influences imposed by the different factors are hereby elaborated as follows.

\section{1) Teacher factors}

According to James, like most teachers, the most important thing for him in his first few years as a teacher was whether he could cover all the content in the textbook, rather than whether the students have actually learned. Subsequently, after participating in the seminars on the reform curriculum, where he reflected on his own teaching and became influenced by the concept of learning community, he began to try different teaching methods in order to stimulate the students' learning motivation and his own passion for teaching. Although the results were far from ideal in the beginning, he did not stop trying and has now come to a relatively satisfactory means of implementation. During the interviews, he kept emphasizing the importance of review, preview, interactions and discussions on the students' mathematics learning:

... during the review of old content and preview of new content, I would help wake up the memories of the children and stimulate their motivation to learn for a fixed time period in every lesson. This has been proved to be very important for their learning afterwards. Before the interactions and discussions, I will design some introductory questions first and help the students to focus on the key points at the right time, thus helping them to develop ideas or concepts in a complete manner. All of these come from the teaching pattern I am currently using, which has been proved useful in helping the students learn or use the mathematics ideas or concepts they are supposed to learn. This pattern also makes sure that these could be turned into part of the students' lasting memory (J1109).

In addition, James also thought that the most important thing for mathematics learning in elementary schools was the comprehension of basic concepts. Combined with consequent practices, the students could become familiar with the concepts and be ensured not to forget them all after the exams. This is why he would not spend all the time on the explanation of concepts or calculations, but always devote some time for the students to have interactions and discussions (J1025). This explains the greater amount of time devoted to practices and discussions in James's classes. 


\section{2) Student factors}

James thought that teachers tended to ignore or spend little time on two teaching activities: preview and review, interactions and discussions. What he found, however, was that preview and review could enhance the students' learning motivation, as a result of which the consequent use of instruction time would be more effective and students would have better outcomes in the mathematics learning. As for interactions and discussions, they provided an opportunity for teachers to refresh their enthusiasm toward teaching in the discussions and thinking generated in the interactions between students and teachers, and those between students. More importantly, the students would be more confident with mathematics learning in the process (J1109). In his classes, therefore, James would divide the students into groups of 3 - 5 and have discussions on specific problems. On the one hand, they could be helped to clarify the concepts. On the other, they could feel the joy of learning as a team. As the students became used to and even fell in love with such discussions and interactions, he began to devote more time to these activities as the lessons advanced. This was a decision made by him in his many years of observations and the effects these activities had on students' learning motivation and performance. Meanwhile, James also found that students could not focus their attention on the class for long. If the teacher kept on explaining new content and methods of calculation, the learning outcomes of the students would not be good. Most of the time, therefore, he would make sure that the time for explanation was about $20 \mathrm{mi}$ nutes. As the explanation came to an end, he would do less explanation of the new content and help the students to enhance learning outcomes through discussions, interactions and practices.

... I tend to spend about only 20 minutes on the explanation of concepts and calculation since the students are not able to concentrate for too long. If you keep explaining for too long, they might take in less. The key to improving learning outcomes lies therefore on the subsequent discussions and practices (J1025).

\section{3) Textbook and contextual factors}

In his teaching, James does not attach much importance to the textbook and contextual factors. Contextual factors, in particular, accounts only for $3.7 \%$ in the interview. Before each lesson, James would make preparations, which could not only give him an overall understanding of the key content in the textbook, but also help him find out the parts that the students might easily be puzzled about. He would also prepare supplementary teaching materials to be used in discussions, interactions and practices in order to help the students enhance their capacities for comprehension and application. In this teaching, therefore, he would not cover all the pages and questions in the textbook as he might be supposed to. In particular, as it is his belief that some practices in the textbook are not relevant to our real life enough, he would usually add several other questions to the lesson. "... In terms of the practices, I tend not to follow the textbook entirely. Instead, I would add some other practices that are related to the application of mathematics in real life ..." (J1025). In terms of contextual factors, James said that al- 
though he would feel stressed because of the schedule, he was able to keep up with the teaching schedule of each unit in a relatively precise manner given his over 20 years of experience as a mathematics teacher. Given moreover that the students were already used to his teaching style and the consequent satisfactory results, he did not find the need to change his instruction implementation or allocation of time because of this stress.

Making preparations before each lesson and having over 20 years of experience as a mathematics teacher, James has a better understanding of the content of the textbook and students' performance. As a result, he would not depend entirely on the mathematics problems in the textbook and design supplementary teaching materials by himself instead in order to help the students clarify their misconceptions or think further. Although the mathematics instruction time of each week is limited, he could still provide more time for the students to have discussions and interactions based on his opinions on mathematics learning and teaching, and the students' learning motivation and interests. Apart from this, he would also provide other mathematics problems not included in the textbook for the students.

\subsection{Discussion}

The use and allocation of mathematics instruction time is not only one of the standards for effective mathematics teaching (Good \& Grouws, 1979), but also the key influence in students' learning (Grouws et al., 2010). It is therefore included as one of the components of OTL (Hiebert \& Grouws, 2007). In the past two decades, although Taiwan is in the course of an educational reform, few studies have been conducted to investigate the use of mathematics instruction time. According to the results of this study, the teacher in this case would not devote too much time on the explanation of new concepts and skills in his mathematics teaching. Instead, he has devoted some time to review and discussions, interactions and practices in every lesson. As the lessons in the unit advances, even more time would be devoted to the students' interactions and discussions, and even less on the development of new content. In other words, as the lessons in the unit advance, the teacher in the case study would gradually transfer the leading role to the students and provide more opportunities for them to have interactions, discussions and practices. The allocation of instruction time by the teacher in this case is therefore more in line with the implementation of teaching activities Grouws et al. (2010) in a reform-oriented mathematics curriculum, and the principles of student-center, interactions between teachers and students, communication and expression that are emphasized in a reform-oriented curriculum (Artzt \& Armour-Thomas, 2002). The factors influential on the use of instruction time by the teacher in this case, based on the categorization in Hsu and Chang (2010), are titled more to the teaching belief of making the students "develop and understand concepts on their own". That is why he has devoted more time to build connections between old and new knowledge and for the students to explore by themselves, discuss and clarify their own misconceptions.

Speaking of the issue of OTL, past studies abroad tended to define the OTL provided 
by a mathematics teacher with the "coverage of textbook content" (Grouws et al., 2013). This is because most of these countries do not have a national curriculum. The amount of teaching content, therefore, constitutes a major influence factor in students' OTL. For countries with a national curriculum, Taiwan for example, is this definition still applicable? In this study, although the teacher would provide supplementary teaching materials, most of the time he is still teaching according to the textbook content. The OTL provided to the students by the teacher in this case lies therefore not on the coverage of content, but the opportunities he creates for the students to think, discuss and communicate. Should we therefore think about and develop the definition of OTL from different perspectives? This awaits many further studies and investigations.

\section{Conclusion and Suggestions}

\subsection{Conclusion}

With a senior teacher having over 20 years teaching experience as the research subject, this study probes into his use of mathematics instruction time and factors influential on this matter. According to the results, the teacher in this case study has a stable pattern for the use of mathematics instruction time: although devoting most time to the development of new content, he would still find time for the other three activities of review and preview, interactions and discussion, practices and applications. As the lessons in a unit advances, he would reduce the time for development of new content, and gradually increase the time for interactions and discussion, practices and applications. In his use of mathematics instruction time, the teacher in this case study tends to rely more on his personal teaching beliefs and the students' interests. His teaching style is therefore more in line with the principle of letting the students develop and understand concepts by themselves. Meanwhile, given his great experience in mathematics teaching and better understanding of the textbook content and the students' learning habits, he is less influenced by textbook and contextual factors.

\subsection{Suggestions}

Based on the findings of this study, the following suggestions are hereby put forward for the reference of future researchers. Firstly, as the number of current studies on the use of instruction time as a research topic is small, whether the use and allocation of instruction time by the teacher in this case study is true to other teachers still awaits further reflection and investigation. Secondly, in terms of OTL, it is found in this study that the OTL provided by the teacher here does not lie in the coverage of textbook content, but in the time he could spare for the students to think and discuss. How the OTL for countries with a national curriculum should be defined therefore also calls for the discussion in future studies. Lastly, more empirical data are needed to examine the relationship between the use of instruction time and students' mathematics learning performance. Only after this could they serve as references for future mathematics education reform. 


\section{References}

Artzt, A., \& Armour-Thomas, E. (2002). Becoming a Reflective Mathematics Teacher: A Guide for Observations and Self-Assessment. Mahwah, NJ: Lawrence Erlbaum.

Boaler, J., \& Staples, M. (2008). Creating Mathematical Futures through an Equitable Teaching Approach: The Case of Railside School. Teacher College Record, 110, 608-645.

Borko, H., \& Livingston, C. (1989). Cognition Improvisation: Differences in Mathematics Instruction by Expert and Novice Teachers. American Education Research Journal, 26, 473-498. http://dx.doi.org/10.3102/00028312026004473

Cuban, L. (1992). Curriculum Stability and Change. In P. W. Jackson (Ed.), Handbook of Research on Curriculum (pp. 216-247). NY: Macmillan.

Even, R., Tirosh, D., \& Robinson, N. (1993). Connectedness in Teaching Equivalent Algebraic Expressions: Novice versus Expert Teachers. Mathematics Education Research Journal, 5, 5059. http://dx.doi.org/10.1007/BF03217254

Fennema, E., \& Franke, M. (1992). Teachers' Knowledge and Its Impact. In D. A. Grouws (Ed.), Handbook of Research on Mathematics Teaching and Learning (pp. 147-164). NY: Macmillan.

Good, T. L., \& Grouws, D. A. (1979). The Missouri Mathematics Effectiveness Project: An Experimental Study in Fourth-Grade Classrooms. Journal of Educational Psychology, 71, 355-362. http://dx.doi.org/10.1037/0022-0663.71.3.355

Grouws, D., Smith, M., \& Sztajn, P. (2004). The Preparation and Teaching Practice of U.S. Mathematics Teachers: Grades 4 and 8. In P. Kloosterman, \& F. Lester (Eds.), The 1990 through 2000 Mathematics Assessments of the National Assessment of Educational Progress: Results and Interpretations (pp. 221-269). Reston, VA: NCTM.

Grouws, D. A., Tarr, J. E., Chávez, Ó., Sears, R., Soria, V. M., \& Taylan, R. D. (2013). Curriculum and Implementation Effects on High School Students' Mathematics Learning from Curricula Representing Subject-Specific and Integrated Content Organizations. Journal for Research in Mathematics Education, 44, 416-463. http://dx.doi.org/10.5951/jresematheduc.44.2.0416

Grouws, D. A., Tarr, J. E., Sears, R., \& Ross, D. J. (2010). Mathematics Teachers' Use of Instructional Time and Relationships to Textbook Content Organization and Class Period Format. Paper Presented at the Hawaii International Conference on Education, Honolulu, HI.

Gutstein, E. (2003). Teaching and Learning Mathematics for Social Justice in an Urban Latino School. Journal for Research in Mathematics Education, 34, 37-73. http://dx.doi.org/10.2307/30034699

Henningsen, M., \& Stein, M. K. (1997). Mathematical Tasks and Student Cognition: Classroom Based Factors That Support and Inhabit High-Level Mathematical Thinking and Reasoning. Journal for Research in Mathematics Education, 28, 524-549. http://dx.doi.org/10.2307/749690

Hiebert, J., Gallimore, R., Garnier, H., Givvin, K. B., Hollingsworth, H., Jacobs, J. et al. (2003). Teaching Mathematics in Seven Countries: Results from the TIMSS 1999 Video Study. Washington DC: National Center for Education Statistic.

Hiebert, J., \& Grouws, D. A. (2007). The Effects of Classroom Mathematics Teaching on Students' Learning. In F. Lester (Ed.), Second Handbook of Research on Mathematics Teaching and Learning (pp. 371-404). Charlotte, NC: Information Age.

Hsu, W. M. (2013a). Examining the Types of Mathematical Tasks Used to Explore the Mathematics Instruction by Elementary School Teachers. Creative Education, 4, 396-404.

http://dx.doi.org/10.4236/ce.2013.46056

Hsu, W. M. (2013b). A Comparison and Analysis of the Types and Representations of Mathematical Problems in the Elementary Mathematics Textbooks of Taiwan, Finland and Singa- 
pore. Chinese Journal of Science Education, 21, 263-289.

Hsu, W. M. (2013c). An Exploratory Study of Mathematics Textbook Use by Elementary School Teachers. Chinese Journal of Science Education, 21, 25-48.

Hsu, W. M., \& Chang, K. K. (2010). The Influence of Mathematics Curriculum of Teacher Education on the Mathematics Teaching Image of Elementary School Teachers: A Case Study. Contemporary Educational Research Quarterly, 18, 41-77.

Leung, F. K. S. (2005). Some Characteristics of East Asian Mathematics Classrooms Based on Data from the TIMSS 1999 Video Study. Educational Studies in Mathematics, 60, 199-215. http://dx.doi.org/10.1007/s10649-005-3835-8

Lloyd, G. (2008). Curriculum Use While Learning to Teach: One Student Teacher's Appropriation of Mathematics Curriculum Materials. Journal for Research in Mathematics Education, $39,63-94$

Mullis, I. V. S., Martin, M. O., Gonzales, E. J., Gregory, K. D., Garden, R. A., O’Cornor, K. M., Chrostowski, S. J., \& Smith, T. A. (2000). TIMSS 1999 International Mathematics Report. Chestnut Hill, MA: International Study Center, Boston College.

Remillard, J. (2005). Examining Key Concepts in Research on Teachers' Use of Mathematics Curricular. Review of Educational Research, 75, 211-246. http://dx.doi.org/10.3102/00346543075002211

Sandt, S. (2007). Research Framework on Mathematics Teacher Behaviour: Koehler and Grouws' Framework Revisited. Eurasia Journal of Mathematics, Science \& Technology Education, 3, 343-350

Stein, M., Remillard, J., \& Smith M. (2007). How Curriculum Influences Student Learning. In F. Lester (Ed.), Second Handbook of Research on Mathematics Teaching and Learning (pp. 319-369). Charlotte, NC: Information Age.

Tarr, J., Reys, R., Reys, B., Chávez, Ó., Shih, J., \& Osterlind, S. (2008). The Impact of MiddleGrades Mathematics Curricula and the Classroom Learning Environment on Student Achievement. Journal for Research in Mathematics Education, 39, 247-280.

Weiss, I. R., Banilower, E. R., McMahon, K, C., \& Smith, P. S. (2001). Report of the 2000 National Survey of Science and Mathematics Education. Chapel Hill, NC: Horizon Research, Inc.

Weiss, I. R., Pasley, J. D., Smith, P. S., Banilower, E. R., \& Heck, D. J. (2003). A Study of K-12 Mathematics and Science Education in the United States. Chapel Hill, NC: Horizon Research, Inc. 
Submit or recommend next manuscript to SCIRP and we will provide best service for you:

Accepting pre-submission inquiries through Email, Facebook, LinkedIn, Twitter, etc. A wide selection of journals (inclusive of 9 subjects, more than 200 journals)

Providing 24-hour high-quality service

User-friendly online submission system

Fair and swift peer-review system

Efficient typesetting and proofreading procedure

Display of the result of downloads and visits, as well as the number of cited articles

Maximum dissemination of your research work

Submit your manuscript at: http://papersubmission.scirp.org/

Or contact ce@scirp.org 